\title{
SUPPLY CHAIN MANAGEMENT SUSTAINABILITY THROUGH THE PERFORMANCE IMPROVEMENT OF MTS-MTO PRODUCTION SYSTEM TYPOLOGY
}

\author{
RIZKI ANISSA \\ International Program of Industrial Engineering, Islamic University of Indonesia, Indonesia, \\ Email : rizkiianissa@gmail.com
}

DOI Number : $10.30988 /$ imil.v1i1.8

\begin{abstract}
Batik has been acknowledged as a Masterpiece of Oral and Intangible Heritage of Humanity of Indonesia based on UNESCO in 2009 and this asset is considerably becoming the prospect to overcome global market in Asia. In the other side, the global competition can only be encountered by sustainably developing the internal industry. Therefore, this research elaborates sustainable supply chain performance assessment and also the improvement framework applied in Batik industry with MTO-MTS typology. For fulfilling the provisions of sustainability, the economic, environmental, and social is strictly important to be involved in. Supply Chain Operations Reference (SCOR) is a reference model of assessment considering five attributes to be measured and implemented as the perspective of economic assessment. Employee's welfare and liquid waste assessment are then becoming the method to measure the social and environmental aspect. This resulted score as: Reliability is $89.24 \%$, Responsiveness for MTS is $96 \%$ for MTO is $62 \%$, Cost is $83.32 \%$, Agility is $100 \%$, and the Assets Management is $79.63 \%$. For the social aspect, the score of parameter Health Insurance is $100 \%$, Safety Tools is $100 \%$, Basic Allowance is $70 \%$, Annual Allowance is $100 \%$, Appropriate Work Hours is $67 \%$, and the Reward is $70 \%$. For the environmental aspect, the temperature is $100 \%$, $\mathrm{pH}$ $62.0 \%$, BOD $100 \%$, COD $64.7 \%$, and TSS $7.4 \%$. The improvement framework is also proposed by using Customer Order Decoupling Point (CODP) that results the increased performance in the Responsiveness attribute in the MTO process as much as $8.25 \%$.
\end{abstract}

Keyword: Sustainable Supply Chain Management, Supply Chain Order Reference, CODP, MTO-MTS. 


\section{INTRODUCTION}

Sustainable development has become the major attention in these recent years. Based on Brundtland (1987), in the past of 25 years, there are numerous industries realized that the level of sustainability has reached the board-level concern. This generated questions about how the sustainability concept can be implemented. In specific, how it should be involved in the strategic levels and operational levels of management decision making. For the internal of the organization, this is acknowledged as sustainable operations management (Gimenez et al., 2012), while for the external of the organization, the effects related to the value chain and supply network are defined as Sustainable Supply Chain Management (SSCM) (Carter and Rogers, 2008).

Based on those elaborations, it can be recognized that the concept SSCM becomes the updating issues to be discussed. The developments do always exist by the idea generation of some researchers, since the environmental awareness of people also increases related to the supply chain impact of industries. Zailani et al. (2012) stated that there is a rapidly increasing awareness in industry that today's supply chains are flawed. To date, many manufacturing companies create waste and pollution and are threatening the existence of life on earth. These concerns push firms into seriously considering the environmental impact while doing their business. The implementation of SSCM is a key enabler that could push organizations to focus on alleviating environmental issues and providing economic and social benefits.

Zailani et al. (2012) observed an investigation about the extent of implementation of SSCM management practices (environmentally purchasing and sustainable packaging) as well as the outcomes of those practices on SSCM. This results positive effect on three categories of outcomes (economic, social and operational) as well as proves that SSCM practices have a positive effect on sustainable supply chain performance, particularly from the economic and social perspective.

Ala-Harja and Helo (2014) analyzed about green supply chain decisions by mainly focusing on the order picking, transportation, warehousing and distribution aspects from the greening point of view. A framework for sustainable performance assessment of SCM practices is generated by providing sustainable performance characterization and an analytical model for sustainable performance assessment (Baumann \& Genoulaz, 2014). Altuntas and Tuna (2013) defined that an effort to decrease negative environmental effects of logistics companies is the geographical concentration of logistics companies which are called logistics centers. It aims to provide a green industrial service buying approach for the industrial customers of logistics center.

From the companies' perspective, they must be acquiring the environmentally friendly image of products, processes, systems and 
technologies, and the way business is conducted (Vachon and Klassen, 2006). According to Porter and Kramer (2006), companies are increasingly expected to extend their sustainability efforts beyond their own operations to include those of their suppliers and to meet their customer's sustainability expectations. Forward thinking companies are already taking steps to develop sustainability within their supply chains. These concerns push firms into seriously considering the environmental impact while doing their business. The implementation of SSCM is a key enabler that could push organizations to focus on alleviating environmental issues, and providing economic and social benefits.

The idea about performance measurement of SSCM is considered as a new knowledge. There has been no framework that develops the performance of its study. One of the models that can be used for the performance assessment of the SCM is Supply Chain Order Reference (SCOR) by Supply Chain Council (SCC). The latest version of SCOR introduced the reference model Green-SCOR as one of performance tools of SSCM. This highlights a number environmentally friendly best practices (environmental management system implementation, recyclable material identification, load maximization, etc.) as well as a set of environmental indicators such as GHG emission, percentage of waste recycled, liquid waste generated, etc. (SCC, 2008). The previous research about SCOR 11.0 is still limited. Chardinebaumann \& Botta-genoulaz (2014) was conducting a research about a framework for sustainable performance characterization and an analytical model for sustainable performance assessment of SCM practices. The framework is used to characterize a company's sustainable performance in the economic, environmental and social fields. The result answers the initial question of how to assess the sustainable performance of SCM practices that can easily be applied to any SCM practice that is considered as a best practice at a given time in a company, or that a company intends to implement. The proposed framework can also be applied by a company in order to highlight those SCM practices that impact its sustainable performance more positively.

This research will primarily focus on the framework development to assess the performance of SSCM. This framework is able to measure the SSCM performance by using SCOR for the economical aspect, liquid waste measurement for the environmental aspect, and the employee's welfare assessment for the social aspect. Additionally, this research provides solution to improve the performance of the attributes in conducting the process of chain. The case will be based on the Batik industry, which the companies are previously clustered based on the type of production.

\section{LITERATURE REVIEW}

SCM is defined as the management of exchanges of materials and information in the logistics process stretching from the purchasing of raw materials to the delivery of end- 
products to end customers, so linking several firms (Cooper et al., 1997). From the companies' perspective, they must be acquiring the environmentally friendly image of products, processes, systems and technologies, and the way business is conducted (Vachon and Klassen, 2006). According to Porter and Kramer (2006), companies are increasingly expected to extend their sustainability efforts beyond their own operations to include those of their suppliers and to meet their customer's sustainability expectations. Forward thinking companies are already taking steps to develop sustain- ability within their supply chains. To date, many manufacturing companies create waste and pollution and are threatening the existence of life on earth. These concerns push firms into seriously considering the environmental impact while doing their business. The implementation of SSCM is a key enabler that could push organizations to focus on alleviating environmental issues, and providing economic and social benefits.

An investigation about the extent of implementation of SSCM management practices (environmentally purchasing and sustainable packaging) as well as the outcomes of those practices on SSCM result positive effect on three categories of outcomes (economic, social and operational) as well as proven that SSCM practices have a positive effect on sustainable supply chain performance, particularly from the economic and social perspective (Zailani et al., 2012).
Even there has been no specific research that discusses about the application of SSCM related to the MTS-MTO type of production, there are numerous frameworks about SSCM. For example, Boukherroub et al. (2014) elaborated an integrated approach for sustainable supply chain planning. It is designed a method that links sustainability performance to supply chain decisions and allows setting coherent performance measures. The result is supply chain planning is optimized while the economic, environmental and social performances are all coherently integrated into the model.

\section{SSCM ASSESSMENT SCOR 11.0}

As the parameter of the financial assessment process of SSCM applied in Batik industry, SCOR 11.0 is implemented. SCOR model was created in 1996 by the Supply Chain Council (SCC, 2000) as a standard framework for companies. It defines a method, reference processes, key indicators and best practices to represent, assess and diagnose the supply chain. The SCOR model proposes five families of metrics for assessing SCM practices: reliability, responsiveness, flexibility, costs, and asset management.

The previous research about SCOR 11.0 is still limited. Chardinebaumann \& Botta-genoulaz (2014) was conducting a research about a framework for sustainable performance characterization and an analytical model for sustainable performance assessment of SCM practices. The 
framework is used to characterize a company's sustainable performance in the economic, environmental and social fields. The result answers the initial question of how to assess the sustainable performance of SCM practices that can easily be applied to any SCM practice that is considered as a best practice at a given time in a company, or that a company intends to implement. The proposed framework can also be applied by a company in order to highlight those SCM practices that impact its sustainable performance more positively.

\section{Palma-mendoza}

elaborated a literature review to result a solution by using the SCOR model, then to use Analytical Hierarchy Process (AHP) analysis for target process selection. AHP can aid in deciding which supply chain processes are better candidates to re-design in light of predefined criteria. The results provided by the AHP analysis go beyond target process selection. From the AHP analysis, it can calculate a priority rank for the metric criteria used.

Xiao, Cai, \& Zhang (2009) built a network-topology structure of cycle quality chain operations reference (CQCOR) model, which realizes the cycle operation by an added quality process of reverse manufacturing. The optimization model can avoid the traditional mercantilism idea. Fuzzy evaluation is applied and it decreases the distortion of unrigorous factors in modeling and improves searching efficiency in the optimizing of cycle quality chain. The model helps to map out a rough framework for supply chain manager to put the sustainable development strategy and resources recycle into practice.

Even if the research about SCOR 11.0 has not been developed, there are several researches conducted using the previous version of SCOR model by SCC. Cesar et al. (2008), proposed a supply chain performance model based on fuzzy logic to predict performance based on causal relationships between metrics of the SCOR version 8.0 model. A descriptive quantitative approach was adopted as research method, based on the prediction model. Statistical analysis of the prediction model results confirmed the relevance of the causal relationships embedded in the model. The findings reinforce the proposition that the adoption of a prediction model based on fuzzy logic and on metrics of the SCOR model seems to be a feasible technique to help managers in the decisionmaking process of managing performance of supply chains.

\section{Liquid Waste Management}

The assessment for environmental aspect is conducted by measuring the Liquid Waste Assessment which is resulted by the company. There are so many parameters to measure the substances of the liquid waste. Samples for BOD, chloride, sulfate, nitrite, nitrate and alkalinity were not filtered and were kept in $50 \mathrm{ml} \mathrm{PE}$ bottles. These parameters were analyzed according to standard methods (APHA, 1998). Heavy metals were measured using spectrophotometric methods (Hach Lange GMBH, Düsseldorf, Germany). 
In addition, Mangimbulude (2009) elaborated that BOD, COD, Norganic matter, ammonia, sulphate and calcium can be used as the parameters of the liquid waste standard assessment applied in the leachate area. The regulation of the local government of Central Java Province also arranges about the standard parameters of liquid waste by using COD, BOD, TSS, pH, and temperature that can be delivered to the surrounding environment (Perda Jateng, 2005).Temperature is a measurement of the average kinetic energy of the molecules in an object or system and $\mathrm{pH}$ measures how acidic the substance is. While Biochemical oxygen demand (BOD) is the amount of dissolved oxygen needed by aerobic biological organisms in a body of water to break down organic material present in a given water sample at certain temperature over a specific time period. The chemical oxygen demand (COD) test is commonly used to indirectly measure the amount of organic compounds in water. In addition, Total suspended solids (TSS) include all particles suspended in water which will not pass through a filter.

\section{Employees' Welfare Assessment}

Due to the social and environmental impacts of industrial activities in supply chains, corporate social responsibility (CSR) has become critical for many international companies. Social factor is one of the main factors of SSCM, as well with the economic and environment factors. Therefore, sustainability has become an important issue in both managers and researches, since managers will increasingly play a major role in writing and instituting CSR policies and code of conduct (Hsueh, 2014).

Corporate social responsibility (CSR), a similar but distinct concept to corporate sustainability, is becoming increasingly popular (Hediger, 2010). Freeman's (1984) stakeholder perspective suggests that firms need to meet the needs of the stakeholders in addition to the shareholders. According to this perspective, stakeholders are critical for the existence of the firm. The basic idea of the stakeholder perspective is that a firm's success depends on how it is able to manage relationships with key groups, such as customers, employees, suppliers, communities, politicians, and owners, each of which can affect its ability to reach its goals (Ihlen, 2008).

With this in mind, stakeholders contribute to a firm's wealth creating activities (Sawyer and Evans, 2010). Additionally, in fast changing and unpredictable environments, socially responsible behavior helps firms to gain support from various external stakeholder groups (Goll and Rasheed, 2004).The CSR performance of the supplier will eventually influence corporate image, goodwill cost, and sales of the downstream company. Many firms recognize the need to strike a balance between profitability and projecting a positive public image by shouldering more social and environmental responsibility (Mozes et al., 2011). In the research conducted by Cruz (2009), which developed a decision support framework for modeling and analysis of supply chain network with CSR, gave the result that 
social responsibility activities can potentially reduce transaction costs, risk, and environmental impact. However, CSR cannot be quickly implemented, but must be absorbed as second nature by the shareholders, managers, and employees of the firm. In order to encourage firms to do so, the economic benefits we are yet again emphasized whenever companies adopt CSR (Agan et al., 2014).

Srinivas (2013) elaborated a research about an attempt to identify welfare facilities and employee's satisfaction level about welfare facilities. Employee's welfare facilities in the organization effect on the behavior of the employees as well as on the productivity of the organization. In order to assure the employees, the management must provide required good facilities to all employees. The management should provide required good facilities to all employees in such way that employees become satisfied and make them work harder, more efficiently and effectively.

\section{Customer Order Decoupling Point (CODP)}

The model of CODP has been developed by Olhager (2013). It discussed on the impact of having the decoupling point at different positions and the distinguishing features for value chain operations upstream the decoupling point. The journal developed model of CODP, which is the point in the material flow where the product is tied to a specific customer order; the basic choices being MTS, MTO, ETO, and ATO (Assembly to Order). As a rule, the CODP coincides with the most important stock point, from where the customer order process starts.

\section{RESEARCH METHODOLOGY Location and Object of Research}

The object of this study is to conduct assessment of the SSCM performance using the proposed model by the tools of SCOR 11.0, Liquid Waste Assessment and Social Welfare Assessment. As it has been elaborated in Chapter 1, SSCM is one of updating issues to be developed in the industrial field. The measurement on this aspect will benefit to comprehend the extent of SSCM performance in the real industry.

In this research, the focus will be on the Batik industry. Batik is one of industries, which rapidly grow in Indonesia. The market is wider as the habit of society that likely to use this product because of its art values as the inheritance of Indonesia's culture. However, the business processes in Batik industry is resulting the economic, environmental and social impact to the company's circumstances. By following to those reasons, the research will measure the SSCM performance by using the proposed assessment model in the Batik industries which have MTS - MTO type of production after it is identified by the clustering process. The industries are clustered from 200 industries of Batik that will specifically be located at Solo, Central Java as one of the Batik iconic cities.

Specifically, the research was conducted at PT. Danar Hadi which applies production type of MTO MTS. The company has been 
introduced to other three parameters of SSCM that covers economical aspect, environmental and social. Thus, the proposed model for the SSCM performance assessment can be executed in this company.

The results will be processed by analytical process with the tools SCOR 11 for the financial and managerial aspect, Liquid Waste Assessment for the environmental aspect, and Social Welfare Assessment for the social aspect. The performance parameters are then defined to be six aspects that are Plan, Source, Make, Deliver, Enable and Return. All of those parameters will be the focus of the research in order to obtain the optimal performance measurement of SSCM. Each of the Performance Parameters has its own Design Parameters.

\section{Position of Research}

The general topic that will be discussed in this research is the SSCM performance assessment and improvement. For the SSCM performance assessment, the type of manufacture to be identified is Batik Industry with the type of production MTS and MTO. The aspects which will be analyzed are economic aspect, environmental aspect, and social aspect. The environmental aspect will be assessed by using SCOR version11.0 with the parameters of Reliability, Responsiveness, Agility, Cost, and Assets Management. The designed parameters for this methodology are Perfect Order Fulfillment, Order Fulfillment Cycle Time, Total Cost to Serve, Cash to Cash Cycle Time, and Upside Supply Chain
Flexibility. For the environmental aspect, liquid waste management will be the methodology to be applied in this research. The liquid waste will be tested related to the parameters of $\mathrm{COD}$, BOD, TSS, $\mathrm{pH}$, and also temperature. The result will be compared with the standard regulation defined by the local government. The social aspect will use the sampling method of the employees for measuring the parameters of the employees' welfare level that has been applied by the company. The designed parameters will be appropriate allowance, insurance, reward, and work hour appropriateness. Those all will result the performance assessment for the whole chain process of SSCM.

In addition, the sub issue of the attribute of SCOR that will be improved is responsiveness. The selected industrial system is production, and the subsystem is scheduling. The method which will be applied is CODP. The SCOR recalculation then will be conducted and the comparison between the initial assessment with the improved performance is executed. The whole process of the knowledge based on development has been elaborated in the K-Chart development at Figure 1. 


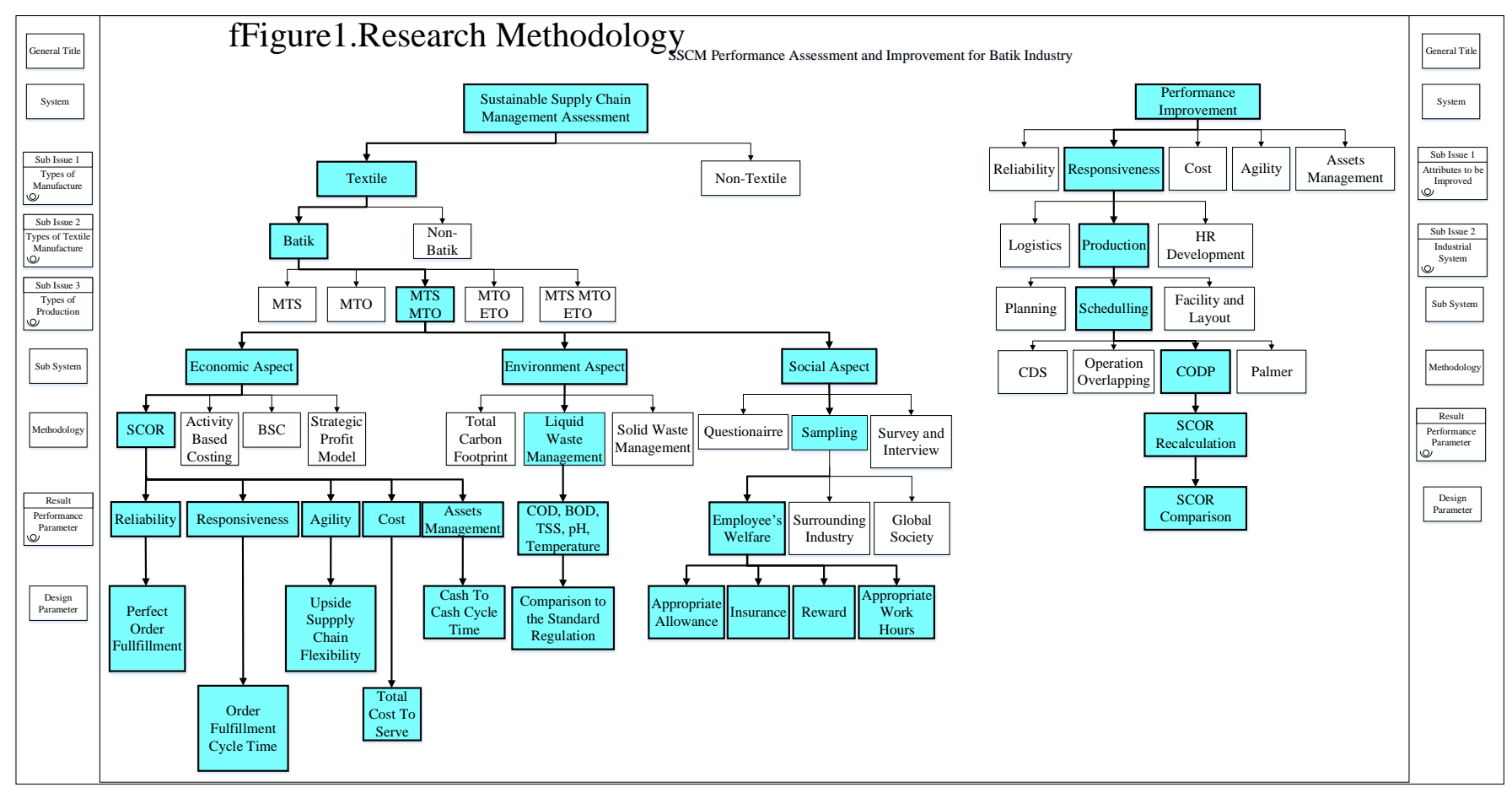




\section{RESULTS AND DISCUSSION GAP ANALYSIS}

The data calculation will be next conducted. The results of the data processing that performs the score of the performance to the SSCM applied in the company will generally elaborated in Table 1 . The score is presented based on each attribute that has been conducted.

Table 1. Score of SSCM Performance

2. Next, the value will be converted to the same unit which is in percentage so the gap can be seen in each attribute. The converted value is shown in the Table 4.3 and the chart that illustrated the distance between the actual score and the target is described in the Figure 2.

Table 2. The Actual Score and the Target

Type of Attribute Assessment Target

Produc

$\begin{array}{cccc}\text { tion } & \text { Plan } & 85.58 \% & \\ \text { MTS - } & \text { Reliablity } & 89.24 \% & 100 \%\end{array}$

MTS- Reliability
MTO

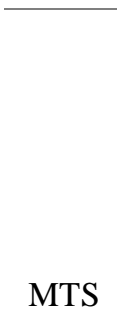

Type of
Production

Attribute

Assessment MTRrget

MTO

Source $\quad 99.38 \%$

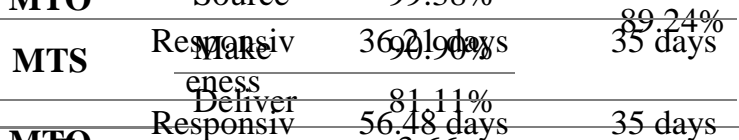
$\begin{array}{rr}\text { Responsiv } & 56.48 \\ \text { efeusce } & 3.66\end{array}$

\begin{tabular}{|c|c|c|c|c|c|}
\hline Production & & & Craste & 28.8 DDR & IDR \\
\hline $\begin{array}{l}\text { MTS - } \\
\text { MTO }\end{array}$ & Reliability & $\begin{array}{c}89.24 \% M^{4} S_{100 \%} \\
\text { MTO }\end{array}$ & Deliver & $1,80 \varphi, 726,0$ & $1,500,000,0$ \\
\hline ITS & Responsivene & $\mathrm{CS}^{100 \%}$ & 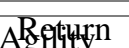 & $100 \%$ & \\
\hline
\end{tabular}

MTS

\begin{tabular}{|c|c|c|c|c|c|}
\hline MTO & & MTO & Deliver & 86.62 & 00.00 \\
\hline MTS & Responsiveness & $96.6 \%$ MTS $^{100 \%}$ & $\mathrm{~A}_{\mathrm{g}}^{\text {Retityn }}$ & $\mathrm{l}_{100 \%}$ & $100 \%$ \\
\hline MTO & Responsiveness & 62\%МТQ00\% & & 1 & \\
\hline $\begin{array}{l}\text { MTS - } \\
\text { MTO }\end{array}$ & Cost & $\begin{array}{c}\text { 83.32\%MTS } 100 \% \\
\text { MTO }\end{array}$ & $\begin{array}{l}\text { Assets } \\
\text { Manageme }\end{array}$ & 150.7 & 36.212 ays \\
\hline
\end{tabular}

\begin{tabular}{ccccc} 
MTO & & \multicolumn{2}{c}{ MTO } & nt \\
\cline { 1 - 3 } MTS - & Agility & $100 \%$ & $100 \%$ & Enable
\end{tabular}

MTO

$\begin{array}{llll}\text { MTS - } & \text { Assets } & 79.63 \% & 100 \%\end{array}$

MTO Management

Table 3. Conversion of the Actual Score and

Responsiveness

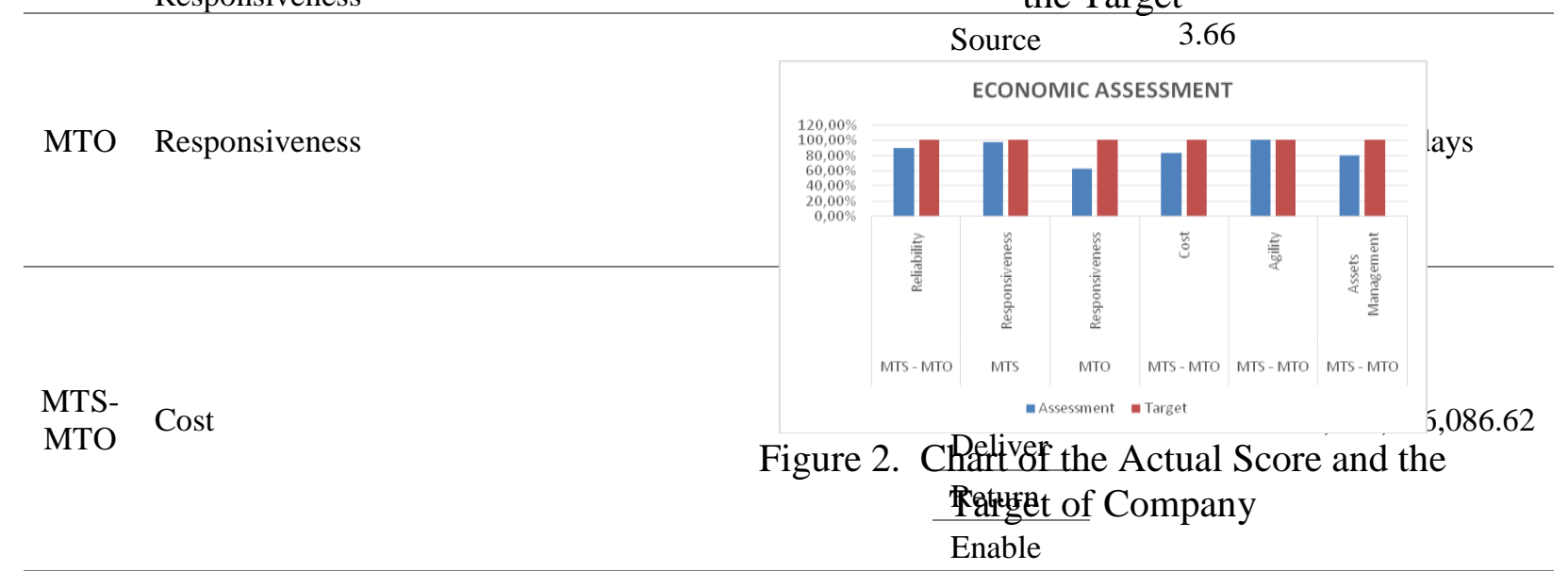

\begin{tabular}{ll}
\hline MTS- & Agility \\
MTO & \\
\hline MTS- & Assets Management \\
MTO
\end{tabular}

The company has set the target that will be achieved after the performance assessment was conducted. The elaboration of the comparison between the actual score and the target that will be achieved is shown in Table
For thesosmal factor,oche results are obtained by theakdistributed oquestionnaires 0 of 50 employees of the company. The method of sampling is Make implemented to understand the percentage of parameters which have been fulfilled by the company. The obtained value of Health Insurance is $100 \%$, Safety Tools is $100 \%$, Basic Allowance is $70 \%$, Annual Allowance is $100 \%$, Appropriate Work Hours 
is $67 \%$, and the Reward is $70 \%$. The result of assessment is shown in Figure 3.

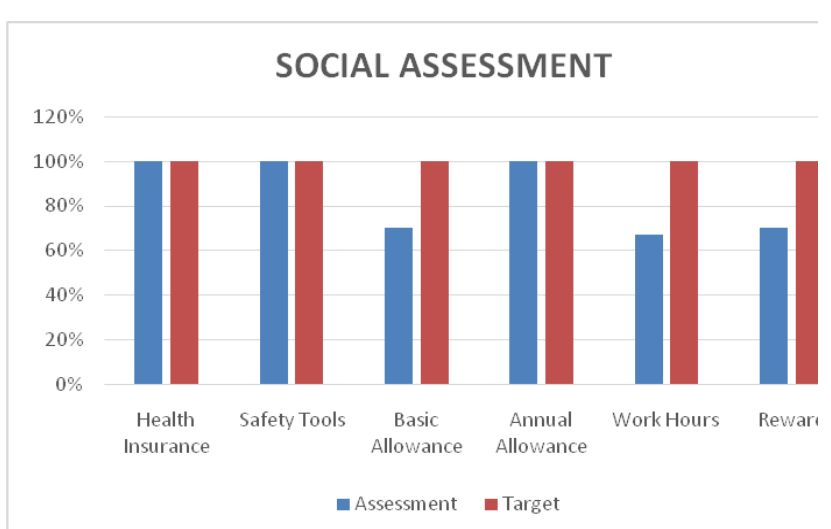

Figure 3. Chart of the Social Assessment

Based on the assessment that has been performed, the value of temperature is $25.4^{\circ}$ $\mathrm{C}$, pH 3.74, the BOD is $18.34 \mathrm{mg} / \mathrm{L}$, the COD is $231.52 \mathrm{mg} / \mathrm{L}$, and TSS is $674 \mathrm{mg} / \mathrm{L}$. While the comparison between the actual condition and the target is shown in Table 4. and the conversion is elaborated in Table 5. The radar chart is illustrated at Figure 4.

Table 4. Environmental Assessment and Target

\begin{tabular}{cc}
\hline Parameter & Actual Conditionf \\
\hline Temperature & 25.4 \\
\hline $\mathrm{pH}$ & 3.74 \\
\hline BOD & 18.34 \\
\hline COD & 231.52 \\
\hline TSS & 674 \\
\hline
\end{tabular}

Table 5. Conversion of Environmental Assessment and Target

\begin{tabular}{ccc}
\hline Parameter & Actual Condition & Target \\
\hline Temperature & $100 \%$ & $100 \%$ \\
\hline $\mathrm{pH}$ & $62.0 \%$ & $100 \%$ \\
\hline BOD & $100 \%$ & $100 \%$ \\
\hline COD & $64.7 \%$ & $100 \%$ \\
\hline TSS & $7.4 \%$ & $100 \%$ \\
\hline
\end{tabular}
process can be started earlier. MTS refers to the faster process than MTO. Since the company applies Hybrid MTS and MTO, the process of MTO that can be conducted using MTS process will be switched to the MTS 
process. The illustration of the repositioning process itself is shown in Figure 6.

Figure 6. Repositioning Process

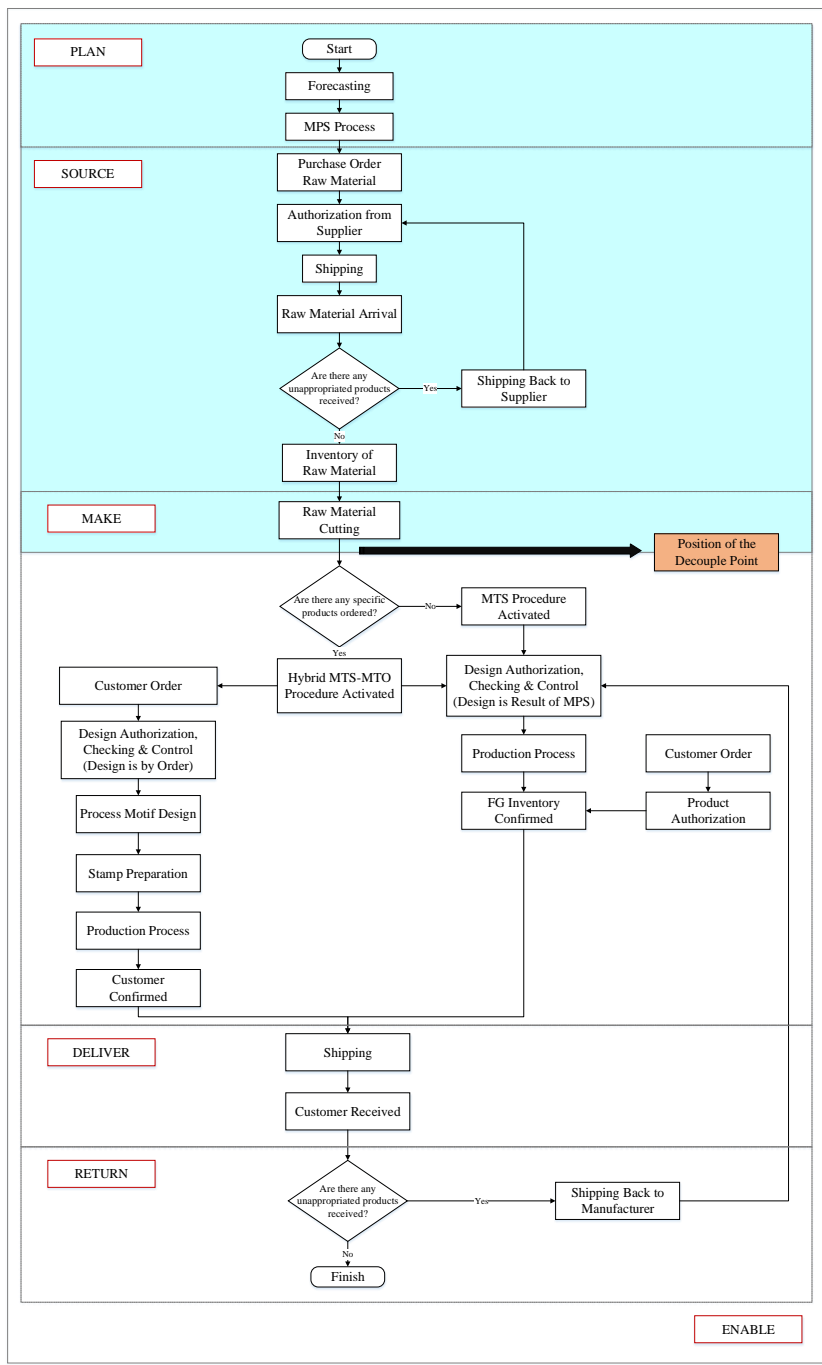

The repositioning process is in the Source process, which are purchase order material, shipping, until the arrival of the raw material. In the MTO process, the raw material order is started when there is an order of the customer. While, MTS process conducts the raw material planning process and purchases the raw material based on those planning processes. The initial MTO can join to the MTS in those processes. The raw material requirements will be added with the raw material for the MTO process by adding the numerous numbers of safety stock. Therefore, when there is order from customer, there will be no lead time to wait the raw material purchasing process because the process has been conducted previously. Additionally, in the Make process of MTO production typology, the cutting raw material process will also be conducted earlier before there is an order from customer. In initial condition, this process is conducted after there is an order from the customer. However, after the CODP is applied, this process can be started earlier before there are orders for MTO product.

Based on the SCOR assessment in the attribute of Responsiveness, it can be obtained that the sum process time for MTS process and MTS Process is resulted by the total of OFCT that are generated by the sum of Source CT, Make CT, Deliver CT, Return CT, and Enable CT. For the MTS Process it results 36.21 days, while for the MTO process it results 56.48 days. If the production refers to the CODP concept, for the customer perspective in the MTO process, the production will not need to wait the raw material purchasing because those have been available. Therefore, the Order Fulfillment Cycle Time for the customer perspective will be shorter to be the sum of Make CT, Deliver CT, Return CT, and Enable CT. In addition, based on the direct observation, the raw material cutting process is always conducted in one day, so the improvement will be added with the duration of this process and it results 51.82 days that the improvement for the MTO process will be reduced as much as 4.66 days for the lead time of customers' perspective. In percentage, the improvement will be $8.25 \%$.

Based on the measurement that has been conducted using the metric of SCOR, the Reliability is obtained $89.24 \%$, Responsiveness for MTS is 36.21 days and MTO is 56.48 days, Cost is IDR $1,800,126,086.62$, Agility is $100 \%$, and the Assets Management is 150.7 days. The company targets each performance as $100 \%$ high. Therefore, the gap between the actual and expectation value are defined as $100 \%$ for Reliability and Agility. While, the expected Responsiveness is 35 days, the Cost is IDR $1,500,000,000.00$, and the Assets 
Management is 120 days. Based on those targets, the percentage value of current condition can be generated as Reliability is $89.24 \%$, Responsiveness for MTS is $96 \%$ for MTO is $62 \%$, Cost is $83.32 \%$, Agility is $100 \%$, and the Assets Management is $79.63 \%$.

For the social factor, the results are obtained by the distributed questionnaires of 50 employees of the company. The method of sampling is implemented to understand the percentage of parameters which have been fulfilled by the company. The obtained value of Health Insurance is $100 \%$, Safety Tools is $100 \%$, Basic Allowance is $70 \%$, Annual Allowance is $100 \%$, Appropriate Work Hours is $67 \%$, and the Reward is $70 \%$.

In addition, for the environmental assessment is defined from the comparison of the COD, BOD, TSS, $\mathrm{pH}$, and temperature between standard regulation of liquid waste for Batik Industry by the local government and the actual condition of the liquid waste resulted. The standard regulation for temperature supposed to be $\leq 38^{\circ} \mathrm{C}$, the BOD $\leq 60 \mathrm{mg} / \mathrm{L}$, the COD $\leq 150 \mathrm{mg} / \mathrm{L}$, and TSS $\leq$ $50 \mathrm{mg} / \mathrm{L}$. Based on the assessment that has been done the value of temperature is $25.4^{\circ} \mathrm{C}$, $\mathrm{pH} 3.74$, the BOD is $18.34 \mathrm{mg} / \mathrm{L}$, the COD is $231.52 \mathrm{mg} / \mathrm{L}$, and TSS is $674 \mathrm{mg} / \mathrm{L}$. Therefore, the converted percentage will be temperature is $100 \%, \mathrm{pH} 62.0 \%$, BOD $100 \%$, COD $64.7 \%$, and TSS $7.4 \%$

Based on the whole assessment, the lowest attribute parameter value of the three aspects of sustainability is on the economical aspect specifically at the Responsiveness attribute. The score is still $73.9 \%$ while the target is $100 \%$. Responsiveness is adequately important since this can define how the ability of the company can response the customers' order. Therefore, this research provides solution to improve the performance of Responsiveness itself. The proposed method is by applying CODP which has ever been elaborated by Lasa et.al. This method focuses to switch the Traditional MTS-MTO on Hybrid MTS-MTO. This proposed method is considered as the state of the art and as the second novelty of this research.
The implemented MTS and MTO in the company have not considered the decoupling point which actually is able to implement to the Hybrid MTS and MTO. MTS refers to the more rapid process, therefore the initial step is by evaluating what process of MTO that can be transformed to be MTS process so this may reduce the production time. The position of decoupling point is the preparation of raw material. In the MTO process, the purchase order is started if there has been any order of customer. However, since the company also applies the MTS type of production, the raw material preparation for the MTO type of production can be processed in the MTS type of production.

After the integration is conducted, the process of SCOR is implemented for the Responsiveness attribute. The lowest score obtained is the Responsiveness at the economic aspects with the current value is 56.48 days. Thus, the proposed framework to improve is by applying CODP to set the decoupling point to which process of MTO that can be substituted by the MTS process. After the CODP is implemented, it can reduce the OFCT for 4.66 days of production which is $8.25 \%$, therefore, this can be concluded that the implementation of CODP can be applied for the improvement process. The results generate new ideas to develop the further research. It is recommended to add the tools to generate future score by using dynamic system. The proposed frameworks can be simulated by considering what factors which is able to influence the future condition of the SSCM.

\section{CONCLUSIONS}

Based on the result of the discussion and referring to the objectives of the research, there are several results which can be concluded as follows:

a. The proposed framework to assess the SSCM applied in Batik Industry is by using SCOR for the economical aspect, liquid waste measurement for the environmental aspect, and the employee's welfare assessment for the social aspect. The attributes implemented in SCOR process are Reliability with Perfect 
Order Fulfillment as the Level 1, Responsiveness with the Order Fulfillment Cycle Time as the Level 1, Cost with the Total Cost to Serve as the Level 1, Agility with Upside Chain Flexibility as the Level 1, and Assets Management with Cash to Cash Cycle Time as the Level 1.

b. The economical aspect for SSCM performance assessment resulted score as follows; Reliability is $85.58 \%$, Responsiveness for MTS is $96 \%$ for MTO is $62 \%$, Cost is $80 \%$, Agility is $100 \%$, and the Assets Management is $74.42 \%$. For the social aspect, the sampling method is applied by considering the factors of Health Insurance, Safety Tools, Appropriate Basic Allowance, Annual Allowance, Appropriate Work Hours, and the Reward. The results show that the score of Health Insurance is $100 \%$, Safety Tools is $100 \%$, Basic Allowance is $70 \%$, Annual Allowance is $100 \%$, Appropriate Work Hours is 67\%, and the Reward is $70 \%$. For the environmental assessment, the converted percentage will be temperature is $100 \%$, $\mathrm{pH} 62.0 \%$, BOD $100 \%$, COD $64.7 \%$, and TSS $7.4 \%$

c. The lowest score obtained is the Responsiveness at the economic aspects with the current value is 56.48 days. Thus, the proposed framework to improve is by applying CODP to set the decoupling point to which process of MTO can be substituted by the MTS process. After the CODP is implemented, it can reduce the OFCT for 4.66 days of production which is $8.25 \%$.

\section{RECOMMENDATIONS}

The whole assessment and improvement processes have been conducted. Based on the process of research, It can be suggested several things that might become the contribution for the future research. Firstly, related to the proposed assessment and improvement framework, the knowledge still can be developed to obtain the future condition by using system dynamics to consider the direct and indirect factors that are able to influence the performance. Secondly, a software for supporting the attributes and levels calculation for the SCOR can also be developed, so the process of assessment can be easier to be conducted. Thirdly, related to the improvement framework, there are still numerous numbers of improvement tools for increasing the performance score, for instance the application of lean manufacturing, six sigma implementation, or mathematical modeling development. Lastly, the tools for obtaining the integrated score that has been including all parameters can be developed, so the score for the whole process of chain is able to be acquired.

\section{REFERENCES}

Ã, C. A. S., Donk, D. P. Van, \& Gaalman, G. (2004). Comparison of dynamic scheduling policies for hybrid make-to-order and make-to-stock production systems with stochastic demand, 104(2006), 441-453. doi:10.1016/j.ijpe.2004.08.002

Agan, Y., Kuzey, C., Acar, M., Acikgoz, A., 2014. The relationship between corporate social responsibility, environmental supplier development, and firm performance. Journal of Cleaner Production. 1-10.

Ala-Harja, H., \& Helo, P. (2014). Green supply chain decisions - Case-based performance analysis from the food industry. Transportation Research Part E: Logistics and Transportation Review, 69, 97-107. doi:10.1016/j.tre.2014.05.015

Alexander, A., Walker, H., \& Naim, M. (2014). Decision theory in sustainable supply chain management: a literature review. doi:10.1108/SCM-01-2014-0007

Altuntaş, C., \& Tuna, O. (2013). Greening Logistics Centers: The Evolution of Industrial Buying Criteria Towards Green. The Asian Journal of Shipping and Logistics, 29(1), 59-80. doi:10.1016/j.ajsl.2013.05.004

APHA, 1998. Standard Methods for Examination of Water and Wastewater, 19th ed. American Public Health Association, Washington, DC.

Boukherroub, T., Ruiz, A., Guinet, A., \& Fondrevelle, J. (2014). An integrated approach for sustainable supply chain planning. Computers \& Operations Research. doi:10.1016/j.cor.2014.09.002

Carter, C.R. and Rogers, D.S. (2008), “A framework of sustainable supply chain management: moving toward new theory", International Journal of Physical Distribution and Logistics Management, Vol. 38 No. 5, pp. 360-387.

Cesar, L., Carpinetti, R., \& Devo, G. M. (2008). Int . J . Production Economics A fuzzy logic approach to supply chain performance management, 134(2011), 177-187. doi:10.1016/j.ijpe.2011.06.011 
Chardine-baumann, E., \& Botta-genoulaz, V. (2006). Computers \& Industrial Engineering A framework for sustainable performance assessment of supply chain management practices. COMPUTERS \& INDUSTRIAL ENGINEERING, 76(2014), 138-147. doi:10.1016/j.cie.2014.07.029

Chardine-Baumann, E., \& Botta-Genoulaz, V. (2014). A Framework For Sustainable Performance Assessment Of Supply Chain Management Practices. Computers \& Industrial Engineering, 76(2014),

$138-147$ doi:10.1016/j.cie.2014.07.029

Cooper, M., Lambert, D., \& Pagh, J. (1997). Supply chain management: More than a new name for logistics. International Journal of Logistics Management, 8(1), 1-14.

Cruz, Jose M. 2009. The impact of corporate social responsibility in supply chain management: multicriteria decision-making approach. Decision Support Systems. 48 224-236.

Freeman, R.E., 1984. Strategic management: a stakeholder approach. Pitman, Boston.

George, Z., Kim, I., Springer, M., George, G., \& Yu, Y. (2013). Int . J . Production Economics Dynamic pooling of make-to-stock and make-to-order operations. Intern. Journal of Production Economics, 144(1), 44-56. doi:10.1016/j.ijpe.2013.01.012

Gimenez, C. and Tachizawa, E.M. (2012), "Extending sustainability to suppliers: a systematic literature review", Supply Chain Management: An International Journal, Vol. 17 No. 5, pp. 531543.

Goll, I., Rasheed, A. A., 2004 The moderating effect of environmental munificence and dynamism on the relationship between discretionary social responsibility and firm performance. J. Bus. Ethics 49, $41 \mathrm{e} 54$.

Mangimbulude, J. C., Breukelen, B. M. Van, Krave, A. S., \& Straalen, N. M. Van. (n.d.). Author' s personal copy Seasonal dynamics in leachate hydrochemistry and natural attenuation in surface run-off water from a tropical landfill. doi:10.1016/j.wasman.2008.06.020

Hediger, W., 2010. Welfare and capital-theoritic foundations of corporate social responsibility and corporate sustainability. J. Socio-Econ. 39, 518-526

Hsueh, C. 2014. Improving corporate social responsibility in a supply chain through a new revenue sharing contract. Int. J. Production Economics. 151, 214-222.

Ihlen, O., 2008. Mapping the environment for corporate social responsibility: stakeholdrs, publics and the public sphere. Corp. Commun. An Int. J. 13, 35-146.

Kerkka, A. (2007). Determining semi-finished products to be stocked when changing the MTS-MTO policy: Case of a steel mill, 108, 111-118. doi:10.1016/j.ijpe.2006.12.006

Kt, S. (n.d.). A Study on Employees Welfare Facilities Adopted at Bosch Limited, Bangalore, 2(12), 7-11.

Leenders, M.R., Johnson, P.F., Flynn, A.E., Fearon, H.E., 2006. Purchasing and Supply Management, 13th edn. Irwin, Burr Ridge, IL.

Mangimbulude, J. C., Breukelen, B. M. Van, Krave, A. S., \& Straalen, N. M. Van. (n.d.). Author' s personal copy Seasonal dynamics in leachate hydrochemistry and natural attenuation in surface run-off water from a tropical landfill. doi:10.1016/j.wasman.2008.06.020

Mozes, M., Josman, Z, Z., Yaniv, E., 2011. Corporate social responsinbility organizational identification and motivation. Soc. Responsibili. $J .7$ (2) 310-325.

Nations, U., \& Assembly, G. (1987). No Title, 25.

Olhager, J. (2012). The Role of Decoupling Points in Value Chain Management. doi:10.1007/978-37908-2747-7

Palma-mendoza, J. A. (2012). International Journal of Information Management Analytical hierarchy process and SCOR model to support supply chain re-design. International Journal of Information Management, 34(5), 634-638. doi:10.1016/j.ijinfomgt.2014.06.002

Porter, M.E., Kramer, M.R., 2006. Strategy and society: the link between compe- titive advantage and corporate social responsibility. Harvard Business Review 84 (12), 78-92.

Rabbani, M., Bagherzadeh, N., \& Rafiei, H. (n.d.). Calculating raw material and work-in-process inventories in MTO / MTS production.

Sawyer, J., Evans., 2010. An investigation into the social and environmental respsonsibility behaviours of regional small business in relation to their impact on the local community and immediate environment. Australas. J. Reg. Stud. $16,253-265$.

Soman, C. A., Donk, D. P. Van, \& Gaalman, G. (2003). Combined make-to-order and make-to-stock in a food production system, 90(2004), 223-235.

Soman, C. A. Ã., Donk, D. P. Van, \& Gaalman, G. J. C. (2007). Capacitated planning and scheduling for combined make-to-order and make-to-stock production in the food industry: An illustrative case study, 108, 191-199. doi:10.1016/j.ijpe.2006.12.042

Sun, X. Y., Ji, P., Sun, L. Y., \& Wang, Y. L. (2008). Positioning multiple decoupling points in a supply network, 113, 943-956. doi:10.1016/j.ijpe.2007.11.012

SCC (2000). Supply chain operations reference model, Cypress, Texas, USA: Supply Chain Council.

SCC (2008). Supply chain operations reference model, Cypress, Texas, USA: Supply Chain Council. Available on: http://supply-chain.org/. 
Vachon, S., Klassen, R.D., 2006a. Extending green practices across the supply chain: the impact of upstream and downstream integration. International Journal of Operations and Production Management 26 (7), 795-821.

WCED (1987). Our common future. Oxford, United Kingdom: Oxford University Press.

Xiao, R., Cai, Z., \& Zhang, X. (2009). An optimization approach to cycle quality network chain based on improved SCOR model. Progress in Natural Science, $\quad$ 19(7), 881-890. doi:10.1016/j.pnsc.2008.11.004

Zailani, S., Jeyaraman, K., Vengadasan, G., \& Premkumar, R. (2012). Sustainable supply chain management (SSCM) in Malaysia: A survey. International Journal of Production Economics, 140(1), $330-340$

doi:10.1016/j.ijpe.2012.02.008 